\title{
Qualidade microbiológica e atividade antimicrobiana de cepas de estafilococos coagulase positiva isolados de sushis
}

\author{
[Microbiological quality and antimicrobial activity of strains of coagulase-positive staphylococci \\ isolated from sushi]
}

\section{"Artigo Científico/Scientific Article"}

\author{
Wanessa Sales de Almeida ${ }^{1}$, Francisco das Chagas Cardoso Filho ${ }^{2}$, \\ Victor Augusto Araújo Barbosa ${ }^{3}$, Luan Monteiro Lima ${ }^{1}$, Rosana Martins Carneiro ${ }^{4}$, \\ Waleska Ferreira de Albuquerque ${ }^{*}$
}

\begin{abstract}
${ }^{1}$ Programa de Pós-Graduação em Alimentos e Nutrição, Universidade Federal do Piauí (UFPI), Teresina-PI, Brasil.
${ }^{2}$ Agência de Defesa Agropecuária do Estado do Ceará (ADAGRI), Crateús-CE, Brasil.

${ }^{3}$ Programa de Pós-Graduação em Ciência Animal, Universidade Federal do Piauí (UFPI), Teresina-PI, Brasil.

${ }^{4}$ Departamento de Informação, Ambiente, Saúde e Produção Alimentícia, Curso de Tecnologia de Alimentos, Instituto

Federal do Piauí (IFPI), Teresina-PI, Brasil.

${ }^{5}$ Coordenação do curso de Farmácia, Universidade Federal do Piauí (UFPI), Teresina-PI, Brasil.

*Autor para correspondência/Corresponding author: E-mail: waleska.@ufpi.edu.br
\end{abstract}

\begin{abstract}
Resumo
O presente trabalho teve como objetivo avaliar a qualidade microbiológica de sushis comercializados em Teresina-PI, retratando o perfil de sensibilidade aos antibióticos de espécies microbianas contaminantes presentes. Foram realizadas seis coletas em quatro restaurantes comercializadores de sushi. As amostras foram analisadas quanto aos parâmetros microbiológicos de coliformes a $35^{\circ} \mathrm{C}$ e $45^{\circ} \mathrm{C}$, pesquisa de Salmonella spp. e de Staphylococcus coagulase positiva, além da contagem de bactérias aeróbias mesófilas. Os microrganismos isolados foram submetidos ao antibiograma. A quantificação de bactérias aeróbias mesófilas variou entre $1 \times 10^{1}$ e $7 \times 10^{4}$. Para coliformes totais, os resultados se apresentaram entre 3,6 e $1,1 \times 10^{3}$ e para coliformes termotolerantes $<3$ e $>1,1 \times 10^{3}$. Em $25 \%$ das amostras foi constatada a presença de Staphylococcus coagulase positiva e em $100 \%$ a ausência de Salmonella spp. Quanto ao antibiograma 14 cepas (70\%) apresentaram sensibilidade a ampicilina $10 \mu \mathrm{g}, 8(40 \%)$ à oxacilina $1 \mu \mathrm{g}$ e todas as cepas testadas $(100 \%)$ foram sensíveis a levofloxacino $5 \mu \mathrm{g}$ e sulfametoxazol $25 \mu \mathrm{g} ; 8$ cepas apresentaram resistência à múltiplos antibióticos. A presença de microrganismos potencialmente patogênicos nas amostras analisadas indica desvios nas Boas Práticas de Fabricação e sinalizam para a necessidade de educação e adequação dos estabelecimentos no que tange às condições higiênico-sanitárias visando a segurança e saúde do consumidor.
\end{abstract}

Palavras-chave: alimentos; coliformes; salmão.

\begin{abstract}
The present study aimed to evaluate the microbiological quality of sushi commercialized in Teresina-PI, portraying the antibiotic sensitivity profile of contaminating microbial species present. Six collections were carried out at four sushi merchants. The samples were analyzed for microbiological parameters of coliforms at $35^{\circ} \mathrm{C}$ and $45^{\circ} \mathrm{C}$, Salmonella spp. and coagulase positive Staphylococcus, in addition to aerobic mesophilic bacteria count. The isolated microorganisms were subjected to antibiogram. The quantification of aerobic mesophilic bacteria varied between $1 \times 10^{1}$ and $7 \times 10^{4}$. For total coliforms, the results were between 3.6 and $1.1 \times 10^{3}$, and for thermotolerant coliforms $<3$ and $>1.1 \times 10^{3}$. In $25 \%$ of the samples, the presence of coagulase positive Staphylococcus was verified, and in $100 \%$, the absence of Salmonella spp. As for the antibiogram, 14 strains (70\%) showed sensitivity to ampicillin $10 \mu \mathrm{g}, 8(40 \%)$ to oxacillin $1 \mu \mathrm{g}$, and all strains tested (100\%) were sensitive to $5 \mu \mathrm{g}$ levofloxacin and $25 \mu \mathrm{g}$ sulfamethoxazole; 8 strains showed resistance to multiple antibiotics. The presence of potentially pathogenic microorganisms in the analyzed samples indicates deviations from the Good Manufacturing Practices and indicate the need for education and adaptation of the establishments with regard to the hygienic and sanitary conditions focusing on the health and safety of the consumer.
\end{abstract}

Keywords: food; coliforms; salmon. 


\section{Introdução}

O consumo de sushi, no Brasil, tem aumentado nos últimos anos (Araújo et al., 2010). Apesar de ser considerado um alimento com alto teor proteico e rico em vitaminas e minerais, o pescado utilizado no preparo desses pratos é considerado um alimento de alto risco (Santos et al., 2012) por apresentar alta atividade de água, ser rico em gorduras oxidáveis e ter $\mathrm{pH}$ próximo à neutralidade (Oliveira e Marques, 2012) formando um ambiente propício para o desenvolvimento de microrganismos (Vieira, 2004).

Durante a preparação de vários pratos feitos à base de pescado, alguns agentes patogênicos podem ser inseridos e acabam por fazer parte do produto final. Quando tal produto é armazenado sob refrigeração ou sofre algum processo de cocção a contaminação, geralmente é minimizada ou mesmo eliminada. Entretanto, o sushi é consumido cru (Oliveira e Marques, 2012).

Por ser preparado manualmente, o contato direto dos manipuladores pode levar à contaminação do sushi por coliformes fecais, como Escherichia coli, bem como por Staphylococcus, ambos causadores de desordens intestinais (Montanari et al., 2015). Os riscos aumentam ainda mais, quando essas preparações são expostas em balcões, muitas vezes à temperatura ambiente, onde podem permanecer por tempo prolongado até serem consumidas (Vallandro et al., 2011).

O uso abusivo de antimicrobianos, seja por aquisição própria ou por prescrição médica inadequada, ocasionou o surgimento de microrganismos resistentes, de tal modo que a indústria farmacêutica tem tido dificuldade em responder à demanda por fármacos potentes e de amplo espectro. O que se observa é uma rápida pressão seletiva a esses fármacos, devido ao desenvolvimento e transferência genética da resistência adquirida (Oliveira et al., 2009).

Os aspectos acima relacionados justificam, do ponto de vista da Saúde Pública, a avaliação da qualidade sanitária dos sushis expostos em restaurantes self-service, levando em consideração a grande quantidade de pessoas que apreciam esse prato e o potencial que o mesmo têm para o desenvolvimento de micro-organismos patogênicos. $O$ fenômeno da resistência, sinaliza a necessidade de avaliar esses microrganismos frente aos principais antibióticos. Ao levarmos em conta todos esses fatos, fica claro que a análise da qualidade desse tipo de produto torna-se necessária, sendo este o objetivo do presente estudo, realizado em restaurantes do tipo selfservice localizados na zona leste da cidade de Teresina, PI.

\section{Material e Métodos}

Os sushis foram adquiridos de quatro restaurantes distintos e identificados pelas letras A, B, C e D. Foram realizadas seis aquisições em cada estabelecimento, em intervalos de 15 dias, totalizando 24 amostras de $100 \mathrm{~g}$ cada. Todas as amostras após a coleta foram acondicionadas em caixas de isopor contendo bolsa de gelo e transportadas para o Laboratório de Microbiologia de Alimentos do Curso de Farmácia da Universidade Federal do Piauí. As análises foram realizadas conforme Silva et al. (2010).

\section{Preparação das amostras}

Após a abertura das embalagens, unidades analíticas de $25 \mathrm{~g}$ foram pesadas e transferidas para um Erlenmeyer com $225 \mathrm{~mL}$ de água peptonada, sendo esta diluição correspondente à diluição $10^{-1}$, ou seja, $10 \mathrm{~g}$ de água peptonada (APT) estéril continha um grama da amostra. A partir da diluição inicial, foram feitas as diluições seriadas $10^{-2} \mathrm{e}$ $10^{-3} \mathrm{em}$ solução salina a $0,85 \%$. As diluições $10^{-1}$, $10^{-2}$ e $10^{-3}$ foram utilizadas para posterior análise microbiológica.

As amostras foram analisadas quanto aos parâmetros microbiológicos por meio da técnica do Número Mais Provável de coliformes a $35^{\circ} \mathrm{C}$ e $45^{\circ} \mathrm{C}$ contagem de bactérias aeróbias mesófilas, pesquisa de Salmonella spp. e de Staphylococcus coagulase positiva segundo a RDC 12/2001, sendo estes últimos submetidos ao antibiograma.

\section{Teste presuntivo para coliformes a $35^{\circ} \mathrm{C}$}

Partindo das diluições $10^{-1}, 10^{-2}$ e $10^{-3}$ foram pipetadas alíquotas de $1 \mathrm{~mL}$ das respectivas diluições para uma série de três tubos de ensaio contendo $9 \mathrm{~mL}$ do Caldo Lauril Sulfato Triptose (CLST) com tubo de Durham invertido. Os tubos foram homogeneizados e incubados a $35-37^{\circ} \mathrm{C}$ por 24-48 horas. Os tubos positivos que, após este tempo, apresentaram turvação e produção de gás (evidenciada no tubo de Durham), passaram imediatamente para a próxima etapa.

\section{Teste confirmatório para coliformes a $35^{\circ} \mathrm{C}$}

Para contagem de coliformes a $35^{\circ} \mathrm{C}$, tomaram-se todos os tubos de CLST com produção de gás e foram transferidas alíquotas de $1 \mathrm{~mL}$ de 
cada cultura para tubos de ensaio contendo $9 \mathrm{~mL}$ de Caldo Bile Verde Brilhante 2\% (CBVB). Os tubos foram incubados a $35-37^{\circ} \mathrm{C}$ por $24-48$ horas, e posteriormente, o número de tubos de CBVB com gás confirmativo da presença de coliformes totais foi comparado com a tabela de NMP apropriada. O resultado foi expresso em NMP de coliformes totais/g.

\section{Teste confirmatório para coliformes a $45{ }^{\circ} \mathrm{C}$}

Para contagem de coliformes a $45^{\circ} \mathrm{C}$ tomaram-se todos os tubos de CLST com produção de gás e foram transferidas alíquotas de $1 \mathrm{~mL}$ de cada cultura para tubos de ensaio contendo $9 \mathrm{~mL}$ de Caldo Escherichia coli (CEC). Os tubos foram incubados em banho-maria a uma temperatura de aproximadamente $45^{\circ} \mathrm{C}$ por 24 horas. Os tubos foram considerados positivos quando apresentaram turvação do meio e produção de gás. Posteriormente, todos os tubos de CEC com gás confirmativo da presença de coliformes foram transferidos, com ajuda de uma alça, para placas de Petri contendo ágar L-EMB que foram incubadas por 12 horas entre $35-37^{\circ} \mathrm{C}$.

\section{Contagem de microrganismos aeróbios mesófilos}

A partir das diluições $10^{-1}, 10^{-2}$ e $10^{-3}$ foi realizada a inoculação utilizando-se a técnica de plaqueamento em superfície (spread plate), de 0,1 $\mathrm{mL}$ de cada diluição em placas de Petri contendo Ágar Padrão para Contagem (PCA). Em seguida, elas foram incubadas em estufa bacteriológica a $35^{\circ} \mathrm{C}$ por $24 / 48$ horas. As placas que, após contagem, apresentaram entre 25 e 250 colônias foram consideradas e posteriormente calculou-se $o$ número de Unidades Formadoras de Colônia por grama de amostra para cada diluição.

\section{Pesquisa e quantificação de Staphylococcus coagulase positiva}

Partindo das diluições seriadas, alíquotas de $100 \mu \mathrm{L}$ foram retiradas e transferidas para placas contendo agar Baird Parker (BP). O conteúdo foi homogeneizado com o auxílio de uma alça de Drigalski estéril. As placas foram levadas à estufa onde permaneceram por 48 horas em uma temperatura de $37^{\circ} \mathrm{C}$. Após esse período, todas as colônias negras foram contadas e as que possuíam bordas regulares com presença de halo de hidrólise foram transferidas, com ajuda de uma alça, para tubos de ensaio contendo Caldo Infusão Cérebro Coração (BHI). Os tubos foram novamente acondicionados em estufa por 24 horas a $35-37^{\circ} \mathrm{C}$. Posteriormente, o teste de coagulase foi realizado e o número de colônias positivas foi comparado aos permitidos pela RDC 12/01.

\section{Presença de Salmonella spp.}

Alíquotas de $25 \mathrm{~g}$ foram homogeneizadas em frasco contendo $225 \mathrm{~mL}$ de APT. Em seguida, foram incubados em estufa de crescimento por 24 horas à temperatura de $35-37^{\circ} \mathrm{C}$. Após este período, alíquotas de $0,1 \mathrm{~mL}$ foram retiradas da APT e inoculadas em 9,9 mL de caldo RappaportVassiliadis. Os tubos foram incubados por 24 horas a temperatura de $42^{\circ} \mathrm{C}$ em banho-maria. Posteriormente, alíquotas foram retiradas com o auxílio de uma alça de níquel-cromo e estriadas em placas de Petri contendo meios diferenciais e seletivos, ágar Entérico Hektoen (HEA) e ágar Salmonella/Shigella (SS), respectivamente. As placas foram então incubadas por 24 horas a 35$37^{\circ} \mathrm{C}$. As colônias que apresentaram crescimento no meio HEA e SS foram então inoculadas em ágar TSI e ágar LIA e incubados por 24 horas a $35-37^{\circ} \mathrm{C}$. A partir do crescimento positivo nos tubos, analisando as características de crescimento das colônias (ácido na base e alcalino no ápice para o meio ágar TSI, e alcalino com ou sem produção de $\mathrm{H}_{2} \mathrm{~S}$ para o meio ágar LIA), detectou-se a presença ou ausência de Salmonella spp. nas amostras.

Teste de sensibilidade in vitro de cepas de Staphylococcus aureus coagulase positiva

Os testes de sensibilidade in vitro foram realizados conforme a metodologia de Bauer et al. (1966), seguindo as recomendações do Clinical and Laboratory Standards Institute (USA, 2013).

\section{Resultados e Discussão}

Constatou-se que 4 das 24 amostras (16,7\%) apresentaram valores $>1,1 \times 10^{3} \quad \mathrm{UFC} / \mathrm{g}$ para coliformes a $35^{\circ} \mathrm{C}$. Um estudo desenvolvido por Guimarães et al. (2016) nas cidades de Crato e Juazeiro do Norte - CE, constatou que $24(80 \%)$ das 30 amostras de sushi do tipo hot roll e de salmão analisadas apresentaram contagem elevada desses microrganismos chegando a uma concentração $\geq 1.100 \mathrm{UFC} / \mathrm{g}$. Embora a RDC 12/01 não estabeleça um limite de tolerância para a presença de coliformes a $35^{\circ} \mathrm{C}$ em sushi, eles indicam uma condição higiênica deficiente o que pode tornar os alimentos impróprios para o consumo humano (Mouta, 2014).

Na Tabela 1, pode-se observar que 5 das 24 amostras (21\%) analisadas apresentaram contagem 
de coliformes a $45^{\circ} \mathrm{C}$ acima do permitido pela RDC 12/01 (BRASIL, 2001), sendo que apenas o restaurante $\mathrm{B}$ não apresentou amostras impróprias para consumo. Resultados semelhantes foram encontrados por Vallandro et al. (2011), em Porto Alegre - RS, que constataram que 23 das 108 amostras (25\%) analisadas apresentavam coliformes termotolerantes acima do permitido $\left(10^{2} \mathrm{UFC} / \mathrm{g}\right)$. A maior quantidade de amostras impróprias para consumo encontrada nesse estudo pode estar relacionada a fatores como desvio nas condições higiênico-sanitárias e não adesão às Boas Práticas de Fabricação.

Tabela 1. Quantidade de microrganismos encontrados em amostras de sushi provenientes de restaurantes self-service especializados em comida japonesa, localizados em Teresina, PI.

\begin{tabular}{|c|c|c|c|c|}
\hline \multirow[b]{2}{*}{ Restaurante } & \multicolumn{2}{|c|}{ NMP/g } & \multirow{2}{*}{$\begin{array}{r}\mathrm{UFC} / \mathrm{g} \\
\mathrm{AM}\end{array}$} & \multirow{2}{*}{$\frac{\mathrm{P} \text { ou A }}{\mathrm{SM}}$} \\
\hline & Coliformes a $35^{\circ} \mathrm{C}$ & Coliformes a $45^{\circ} \mathrm{C}$ & & \\
\hline \multirow{5}{*}{ A } & $4,6 \times 10^{2}$ & $9,3 \times 10^{1}$ & $6,5 \times 10^{3}$ & $\mathrm{~A}$ \\
\hline & 3 & 3 & $1,3 \times 10^{3}$ & A \\
\hline & $>1,1 \times 10^{3}$ & $1,1 \times 10^{3}$ & $3,6 \times 10^{4}$ & $\mathrm{~A}$ \\
\hline & $>1,1 \times 10^{3}$ & $1,1 \times 10^{3}$ & $2,5 \times 10^{4}$ & A \\
\hline & 9,3 & $2,3 \times 10^{1}$ & $8 \times 10^{3}$ & A \\
\hline \multirow{7}{*}{ B } & $2,4 \times 10^{2}$ & $4,3 \times 10^{1}$ & $1,5 \times 10^{3}$ & A \\
\hline & 9,2 & 9,2 & $4,0 \times 10^{2 *}$ & A \\
\hline & 9,2 & 9,2 & $1,7 \times 10^{3}$ & A \\
\hline & $1,5 \times 10^{1}$ & 9,2 & - & A \\
\hline & 9,2 & $<3$ & $3,5 \times 10^{2}$ & A \\
\hline & 3,6 & 3,6 & $1,3 \times 10^{4}$ & A \\
\hline & $2,3 \times 101$ & 3,6 & $<1,0 \times 10^{1 *}$ & A \\
\hline \multirow{6}{*}{$\mathrm{C}$} & 7,4 & 7,4 & $1,1 \times 10^{3}$ & A \\
\hline & $>1,1 \times 10^{3}$ & $1,1 \times 10^{3}$ & $7,0 \times 10^{4}$ & A \\
\hline & $9,3 \times 10^{1}$ & $1,5 \times 10^{1}$ & $7,0 \times 10^{4}$ & A \\
\hline & $1,4 \times 10^{1}$ & 9,2 & $2,7 \times 10^{3}$ & A \\
\hline & 3,6 & 3,6 & $5,0 \times 10^{3}$ & A \\
\hline & $2,3 \times 10^{1}$ & 3,6 & $<1,0 \times 10^{1 *}$ & A \\
\hline \multirow{6}{*}{$\mathrm{D}$} & 9,2 & 9,2 & $4,6 \times 10^{2}$ & A \\
\hline & $>1,1 \times 10^{3}$ & $>1,1 \times 10^{3}$ & $1,6 \times 10^{4}$ & A \\
\hline & 9,2 & 9,2 & $8,5 \times 10^{3}$ & A \\
\hline & $2,9 \times 10^{2}$ & $>1,1 \times 10^{3}$ & $1,4 \times 10^{4}$ & A \\
\hline & $9,3 \times 10^{1}$ & $9,3 \times 10^{1}$ & $1,4 \times 10^{4}$ & A \\
\hline & 9,2 & 3,6 & $3,0 \times 10^{2}$ & A \\
\hline
\end{tabular}

A partir dos coliformes a $45^{\circ} \mathrm{C}$ confirmados pelas provas de Caldo Escherichia coli e Caldo Verde Brilhante, não se obteve nenhuma cepa de $E$. coli, visto que as provas bioquímicas confirmatórias realizadas, utilizando a metodologia INVIC, expressaram resultados negativos.

O pescado pode atuar como um veiculador de microrganismos patogênicos, sendo um dos mais importantes, o Staphylococcus. A presença dele em alimentos evidencia problemas na preparação ou na conservação do produto final e pode acarretar nas pessoas acometidas desde uma intoxicação até internações hospitalares e óbito (Ribeiro et al., 2009).

Seis das 24 amostras (25\%) apresentaram contagem de Staphylococcus coagulase positiva acima do permitido $\left(5 \times 10^{3} \mathrm{UFC} / \mathrm{g}\right)$ pela $\mathrm{RDC}$ 12/2001. Em trabalho desenvolvido por Santos et al. (2012) em Aracaju - SE quatro das 35 amostras $(11,4 \%)$ de sushi analisadas apresentavam essa bactéria em níveis elevados (acima de $5 \times 10^{3}$ UFC/g). Souza et al. (2015) em João Pessoa - PB, constataram que apenas 6,6\% das amostras de sushis pesquisadas apresentaram cepas de Staphylococcus positivas na prova da coagulase.

Das amostras analisadas neste estudo, foram isoladas 20 cepas de Staphylococcus coagulase positiva (SCP), sendo 11 delas $(55,0 \%)$ advindas do restaurante A, $2(10,0 \%)$ do restaurante $\mathrm{B}, 1$ $(5,0 \%)$ do restaurante $\mathrm{C}$ e $6(30,0 \%)$ do restaurante D. 
Ao constatar a existência de Staphylococcus em ao menos uma amostra em todos os restaurantes pesquisados e levando em consideração o fato de a presença desses microrganismos em alimentos estar relacionada a desvios nas boas práticas de fabricação, entende-se que em todos os estabelecimentos, em alguma ocasião, houve deficiência nas práticas de higiene, visto que essa bactéria é um habitante comum das mucosas e pele humana sendo a sua presença em alimentos oriunda de contaminação durante a manipulação.

A RDC 12/2001 preconiza que além de coliformes a $45^{\circ} \mathrm{C}$ e Staphylococcus coagulase positiva a pesquisa de Salmonella ssp. também seja realizada em pratos prontos para o consumo.

Todas as amostras de sushis analisadas apresentaram ausência de Salmonella spp. (Tabela 1) estando em conformidade com a legislação vigente que preconiza a ausência desse microrganismo em pratos prontos à base de pescado. Resultado semelhante foi encontrado por Santos et al. (2012) em Recife - PE ao analisar sushis e, Resende et al., (2009) ao estudar sushis e sashimis comercializados por restaurantes em Brasília - DF, que também não constataram a presença de Salmonella em nenhuma das amostras pesquisadas

Outro importante indicador da qualidade dos alimentos é a pesquisa de microrganismos aeróbios mesófilos. A sua presença em alimentos não está diretamente relacionada à presença de patógenos $\mathrm{e}$ toxinas (Silva et al., 2010). Entretanto, sua contagem é um parâmetro que permite analisar se a limpeza, desinfecção e controle da temperatura durante os processos de tratamento, transporte e armazenamento foram realizados de forma adequada (Silva, 2003). Na Tabela 1 é possível visualizar o resultado da pesquisa de aeróbios mesófilos nas 24 amostras de sushi analisadas. No estudo a quantificação de aeróbios mesófilos variou entre $1 \times 10^{1}$ e $7 \times 10^{4} \mathrm{UFC} / \mathrm{g}$.
A legislação brasileira não estabelece um valor de tolerância para a presença de bactérias aeróbias mesófilas em pescado. Isso torna a correlação de dados difícil, visto que há poucos trabalhos publicados que analisaram esse parâmetro (Lazarin et al., 2012). Assim sendo, não dispomos de um padrão para comparar os resultados obtidos. No entanto, sabe-se que a ausência de microrganismos desse tipo indica que as condições de manipulação e conservação foram adequadas (Souza et al., 2015).

Pela análise dos dados, infere-se que o restaurante A apresentou as piores condições sanitárias relacionadas ao manipulador, visto que a presença de cepas de Staphylococcus coagulase positiva em sushi é comumente associada à sua presença natural na pele e mucosas humana e a transferência desses patógenos para o alimento se dá devido à ineficiência de boas práticas de manipulação e higiene, sinalizando que a contaminação foi decorrente do contato alimentomanipulador.

Os resultados do antibiograma das cepas de Staphylococcus coagulase positiva, estão expressos na Tabela 2, mostrando que 14 das 20 cepas isoladas $(70,0 \%)$ apesentaram sensibilidade à ampicilina e $8(40,0 \%)$ à oxacilina. Já para a azitromicina, 15 das 20 cepas $(75,0 \%)$ apresentaram sensibilidade; para a clindamicina 5 cepas foram sensíveis $(25,0 \%)$; para a tetraciclina 19 das 20 cepas $(95,0 \%)$, e quanto a levofloxacino e o sulfametoxazol todas as 20 cepas (100\%) demonstraram sensibilidade. Em se tratando de resistência, os antimicrobianos com maiores porcentagens foram a ampicilina com 6 de 20 cepas $(30,0 \%)$ e oxacilina com 9 de $20(45,0 \%)$; quanto à azitromicina e clindamicina, houve resistência em $5(25,0 \%)$ e $3(15,0 \%)$ das 20 cepas isoladas, respectivamente. Somente uma amostra (5\%), apresentou resistência à tetraciclina.

Tabela 2. Susceptibilidade antimicrobiana das cepas de Staphylococcus coagulase positiva isoladas de amostras de sushi colhidas em restaurantes especializados da zona leste de Teresina - PI.

\begin{tabular}{|c|c|c|c|c|c|c|c|}
\hline \multirow[t]{2}{*}{ Antibióticos } & \multicolumn{2}{|c|}{ Sensível } & \multicolumn{2}{|r|}{ Intermediária } & \multicolumn{2}{|c|}{ Resistente } & \\
\hline & $\mathrm{N}^{\mathrm{o}}$ & $\%$ & $\mathrm{~N}^{\mathrm{o}}$ & $\%$ & $\mathrm{~N}^{\mathrm{o}}$ & $\%$ & \\
\hline Ampicilina $10 \mu \mathrm{g}$ & 14 & 70,0 & & 0 & 0 & 6 & 30,0 \\
\hline Oxacilina $1 \mu \mathrm{g}$ & 8 & 40,0 & & 3 & 15,0 & 9 & 45,0 \\
\hline Azitromicina $15 \mu \mathrm{g}$ & 15 & 75,0 & & 0 & 0 & 5 & 25,0 \\
\hline Clindamicina $2 \mu \mathrm{g}$ & 5 & 25,0 & & 12 & 60,0 & 3 & 15,0 \\
\hline Sulfametoxazol $25 \mu \mathrm{g}$ & 20 & 100 & & 0 & 0 & 0 & 0 \\
\hline Levofloxacino $5 \mu \mathrm{g}$ & 20 & 100 & & 0 & 0 & 0 & 0 \\
\hline Tetraciclina $30 \mu \mathrm{g}$ & 19 & 95,0 & & 0 & 0 & 1 & 5,0 \\
\hline
\end{tabular}

Legenda: $\mathrm{N}^{\circ}$ : número em quantidade das cepas; \%: porcentagem expressada das cepas. $\boldsymbol{\mu g}$ 
De acordo com um estudo realizado em Portugal por Pereira et al. (2009), em que vários alimentos foram analisados (incluindo carnes cruas, produtos cárneos fermentados tradicionais portugueses, queijos, leite cru proveniente de vacas saudáveis e outros produtos alimentícios), obtevese uma determinada suscetibilidade aos antimicrobianos para isolados de Staphylococcus, sendo que a resistência a $\beta$-lactâmicos, como ampicilina e oxacilina, foi evidente em $70,0 \%$ das 148 cepas isoladas, sendo maior que o percentual encontrado nesse estudo, que foi de $30,0 \%$ para a ampicilina e $45,0 \%$ para a oxacilina.

Como foi observado, não houve resistência ao fármaco sulfametoxazol, sendo todas as 20 cepas sensíveis (100\%), fato esse que divergiu de Noor et al. (2013), que ao analisarem peixes marinhos em Bangladesh obtiveram 24 cepas de $S$. aureus, que apresentaram 70,0\% de susceptibilidade ao sulfametoxazol $25 \mu \mathrm{g}$.

Em estudo Yucel et al., (2011), das 284 cepas de $S$. aureus isoladas de amostra de alimentos (frango, leite cru e queijo), 98,6\% se apresentaram sensíveis ao levofloxacino, corroborando assim com os dados aqui obtidos, demonstrando que todas as cepas de SCP (100\%) isoladas do sushi apresentam sensibilidade a este antimicrobiano.

Os resultados obtidos da análise com a tetraciclina, não corroboram com os estudos realizados por Sánchez et al., (2012), que analisaram produtos derivados da pesca comercializadas na região da Galiza, Espanha, obtendo resistência a tetraciclina em $80,0 \%$ dos produtos prontos para comer, $76,0 \%$ em produtos frescos e $64,3 \%$ em produtos congelados.

Dentre as cepas analisadas, observadas na Tabela 3, nenhuma apresentou sensibilidade a todos os antimicrobianos e as $20(100 \%)$ cepas dos isolados foram resistentes intermediárias ou resistentes a pelo menos um antimicrobiano testado. Dentre os isolados não multirresistentes, $12(60,0 \%)$ eram resistentes intermediários ou resistentes a pelo menos um antimicrobiano.

Tabela 3. Nível de resistência aos microbianos dos isolados de Staphylococcus coagulase positiva obtidas de sushi.

\begin{tabular}{lc}
\hline \multicolumn{1}{c}{ Tipos de cepas } & Número de cepas \\
Sensíveis a todos os antimicrobianos testados & $0(0 \%)$ \\
Resistência intermediária ou resistência a pelo menos um antimicrobiano testado & $20(100 \%)$ \\
Resistentes a duas ou mais classes de antimicrobianos & $8(40 \%)$ \\
Resistência intermediária ou resistência a pelo menos um antimicrobiano testado & $12(60 \%)$ \\
e não multirresistente & $20(100 \%)$ \\
Total de isolados testados & \\
\hline
\end{tabular}

O fenômeno de multirresistência caracteriza-se pela resistência bacteriana a determinadas opções terapêuticas, geralmente a duas ou mais classes de antimicrobianos disponíveis para o tratamento da infecção, para as quais as bactérias são habitualmente sensíveis (Albuquerque et al., 2007). A multirresistência é um fenômeno biológico considerado iatrogênico, ou seja, consequência de tratamentos inadequados e irregulares pela tomada dos medicamentos ou pela utilização dos esquemas terapêuticos padronizados (Queiroz et al., 2012).

A presença de cepas de Staphylococcus com resistência múltipla tem sido relatada em hospitais, principalmente para a oxacilina e cloranfenicol. Por outro lado, linhagens isoladas de indústria de alimentos têm apresentado geralmente baixa resistência para os mesmos fármacos (Novaes, 2013). Como exposto, geralmente o perfil de multirresistência é pouco disseminado em processamento alimentício. Entretanto pelo que foi constatado neste estudo, $8(40,0 \%)$ amostras apresentaram o fenômeno citado, sendo 4 (50,0\%) associado a dois fármacos, $3(37,5 \%)$ a três fármacos e $1(12,5 \%)$ cepa com perfil de resistência frente a quatro fármacos.

A verdadeira importância da presença de resistência antimicrobiana em alimentos ainda é incerta, embora Rapini et al., (2004) apontaram que os alimentos são importantes fatores de transferência de resistência a antibióticos, ao promoverem a ingestão de bactérias resistentes que estejam presentes como contaminantes no alimento e que podem levar à seleção direcionada de cepas resistentes no trato gastrointestinal humano, pela transferência de genes a outros microrganismos patogênicos.

As Boas Práticas de Fabricação abrangem um conjunto de medidas que devem ser adotadas pela indústria de alimentos, bem como por estabelecimentos que ofereçam produtos alimentícios, a fim de garantir a qualidade sanitária do que é consumido pela população (BRASIL, 2002). Nas coletas realizadas nos quatro 
estabelecimentos, foi possível observar de forma visual várias irregularidades quanto à produção e exposição do sushi. Em todos eles os pratos prontos estavam sem nenhum tipo de conservação térmica, sendo comercializados à temperatura ambiente, protegidos apenas por filme plástico e os utensílios utilizados para servir não apresentavam proteção alguma.

A contaminação por coliformes a $45^{\circ} \mathrm{C}$ e Staphylococcus coagulase positiva acima do permitido pela legislação vigente, além da contagem elevada de micro-organismos aeróbios mesófilos, reforça a necessidade do controle de qualidade dos sushis comercializados em Teresina (PI). Os sushis não apresentaram contaminação por Salmonella spp.

\section{Conclusão}

O presente trabalho demonstra a necessidade de um maior controle nos estabelecimentos que comercializam pratos prontos do tipo sushi quanto às condições de conservação e manipulação desses alimentos garantindo assim produtos de qualidade e que atendam às legislações vigentes quanto aos parâmetros microbiológicos e higiênico-sanitários.

\section{Conflito de Interesse}

Nenhum conflito de interesse declarado.

\section{Referências}

Albuquerque, W.F.; Macrae, A.; Sousa, O.V.; Vieira, G.H.F.; Vieira, R.H.S.F. Multiple drug resistant Staphylococcus aureus strains isolated from a fish market and from fish handlers. Brazilian Journal of Microbiology, 38(1): 131-134, 2007.

Araújo, T.D.S.; Freiras, M. J. S.; Silva, S.R.O.; Rebouças, R.H. Sushi: risco microbiológico? Arquivos de Ciências do Mar, 49(1): 55-58, 2016.

BRASIL. Agência Nacional de Vigilância Sanitária. RDC n⿳0. 12, de 02 de janeiro de 2001. Regulamento Técnico sobre os Padrões Microbiológicos para Alimentos. Disponível em 〈http://anvisa.gov.br/legis>. Acesso em: 11 abr. 2018.USA. Performance standards for antimicrobial susceptibility Testing; Twenty-Third Informational Supplement. CLSI document M100-S23. Wayne, Pennsylvania: Clinical and Laboratory Standards Institute 2013. Disponível em <http://www.facm.ucl.ac.be/intranet/CLSI/C
LSI-M100S23-susceptibility-testing-2013no-protection.pdf $>$. Acesso em: 11 abr. 2018. Guimarães, K.P.; Silva, R.M.R.; Guimarães, K.P. Investigação da qualidade microbiológica de sushis comercializados nas cidades de Crato e Juazeiro do Norte - CE. Revista e-Ciência, 4(2): 20-25, 2016.

Lanzarin, M. Quantificação de bactérias heterotróficas aeróbias mesófilas e ocorrência de Salmonella spp. em híbrido de tabacu (Piaractus mesopotamicus x Colossoma macropomum), comercializado em Cuiabá, Mato Grosso. Enciclopédia Biosfera, 8(15): 1500-1509, 2012.

Montanari, A.S.; Romão, N.F.; Sobral, F.O.S.; Marmitt, B.G.; Silva, F.P.S.; Correio, T.C.A.M. Avaliação da qualidade microbiológica de sashimis de salmão, preparados e comercializados em restaurantes japonês no município de Ji-Paraná - RO. South American Journal of Basic Education, Technical and Technological, 2(1): 4-16, 2015.

Mouta, R.M.A.; Melo, M.B.; Araújo, A.B.; Aguiar, F.L.L.; Fontenelle, R.O.S. Qualidade microbiológica do sushi comercializado na cidade de Sobral - CE. Revista da Universidade Vale do Rio Verde, 12(2): 277-284, 2014.

Noor, R.; Acharjee, M.; Ahmed, T.; Das, K.K.; Paul, L.; Munshi, S.K.; Urmi, N. J.; Rahman, F.; Alam, M. Z. Microbiological study of major sea fish available in local markets of Dhaka City, Bangladesh. Journal of Microbiology, Biotechnology and Food Sciences, 2(4): 2420-2430, 2013

Oliveira, A.C.; Damasceno, Q.S.; Ribeiro, S.M.C. $\mathrm{P}$. Infecções relacionadas à assistência em saúde: desafios para a prevenção e controle. Revista Mineira de Enfermagem, 13(3): 445-450, 2009.

Oliveira, T.; Marques, L. Avaliação das condições higiênico-sanitárias no preparo de sushi e sashimi de um estabelecimento comercial. Revista Semiárido De Visu, 2(1): 194-201, 2012.

Pereira, V.; Lopes, C.; Castro, A.; Silva, J.; Gibbs, P. Teixeira, P. Characterization for enterotoxin production, virulence factors, and antibiotic susceptibility of Staphylococcus aureus isolates from various foods in Portugal. Food Microbiology, 26: 278-282, 2009. 
Queiroz, E.M.; Bertolozzi, M.R. Tuberculosis: supervised treatment in North, West and East Health Departments of São Paulo. Revista da Escola de Enfermagem da USP, 44(2): 45361, 2012.

Rapini, L.S.; Teixeira, J.P.; Martins, N.E.; Cerqueira, M.M.O.P.; Souza, M.R.; Penna, C.F.A.M. Perfil de resistência antimicrobiana de cepas de Staphylococcus sp. isolados de queijo tipo coalho. Arquivo Brasileiro de Medicina Veterinária e Zootecnia, 56(1): 130-133, 2004.

Resende, A.; Oliveira, Y.S.; Souza, J.R. Análise microbiológica de sushis e sashimis comercializados em restaurantes de Brasília no período de 2001 a 2004. Higiene Alimentar, 23(174-175): 164-170, 2009.

Ribeiro, A.L. Avaliação microbiológica da qualidade do pescado processado, importado no estado do Rio de Janeiro. Revista Brasileira de Ciência Veterinária, 16(3): 109-112, 2009.

Sánchez, D.V.; Cabo, M.L.; Ibusquiza, P.S.A.A.; Herrera, J. J. R. Incidence and characterization of Staphylococcus aureus in fishery products marketed in Galicia (Northwest Spain). International Journal of Food Microbiology, 157(2): 286-296, 2012.

Santos, A. Avaliação da qualidade microbiológica de sushi comercializado em restaurantes de Aracaju, Sergipe. Scientia Plena, 8(3), 1-5, 2012.
Silva, M.C., Gallo, C.R. Avaliação da qualidade microbiológica de alimentos com a utilização de metodologias convencionais e do sistema simplate. Higiene Alimentar, 17(107): 75-85, 2003.

Silva, N. Manual de métodos de análise microbiológica de alimentos e água. $4^{\mathrm{a}} \mathrm{ed}$. São Paulo: Varela, 2010. 624p.

Souza, G.C.; Santos, C.T.B.; Andrade, A.A.; Alves, L. Comida de rua: avaliação das condições higiênico-sanitárias de manipuladores de alimentos. Ciência \& Saúde Coletiva, 20(8): 2329-2338, 2015.

Souza, T.J.F.F.; Silva Filho, C.R.M.; Santos, J.G. Microorganismos de interesse sanitário em sushis. Revista do Instituto Adolfo Lutz, 74(3): 274-279, 2015.

Vallandro, M.J.; Campos, T.; Paim, D.; Cardoso, M.; Kindlein, L. Avaliação da qualidade microbiológica de sashimis à base de salmão, preparados em restaurantes especializados em culinária japonesa. Revista do Instituto Adolfo Lutz, 70(2): 144-150, 2011.

Vieira, R.H.S F. Microbiologia, higiene e qualidade do pescado: teoria e prática. São Paulo: Varela, 2004. 380p.

Yucel, N.; Citak, S.; Bayhun, S. Antimicrobial resistance profile of Staphylococcus aureus isolated from clinical samples and foods of animal origin. Foodborne Pathogens and Disease, 8(3), 427-31, 2011. 